\title{
Programa Um Computador Por Aluno (PROUCA): uma análise bibliométrica
}

\section{Program One Laptop per Student (PROUCA): a bibliometric analysis}

\author{
Wagner Bandeira Andriola ${ }^{1}$ \\ Carlos Adriano Santos Gomes ${ }^{1}$
}

\begin{abstract}
RESUMO
O avanço da produção científica trouxe consigo o crescimento de estudos que procuram inventariar as pesquisas publicadas, convertendo-se em importantes termômetros do grau de profundidade e de amplitude dessas. Ademais, essa estratégia de pesquisa aponta tendências, lacunas, espaços de saturação, métodos mais recorrentes, obras de referência, dentre outros tantos aspectos relativos às pesquisas e à produção científica oriunda dessas. Assim, esta pesquisa objetivou analisar características demográficas e metodológicas das teses e dissertações produzidas no Brasil acerca do Programa Um Computador por Aluno (PROUCA). Metodologicamente o estudo teve caráter descritivo e recorreu ao procedimento documental, com análise de conteúdo de 43 teses e dissertações publicadas no período 2008 a 2014. Os resultados apontaram: (a) ápice da produção científica sobre o PROUCA entre 2012 e 2013; (b) forte concentração de pesquisas nas regiões sul e sudeste; (c) prevalência de estudos de caso e (d) emprego majoritário de referências bibliográficas nacionais.
\end{abstract}

Palavras-chave: Tecnologia da Informação e Comunicação (TIC); avaliação de programas sociais; tecnologia educacional.

\begin{abstract}
The advancement of scientific production brought with it the growth of studies to take stock of published research, becoming important thermometers on the depth and breadth degree of these. Furthermore, this research
\end{abstract}

DOI: $10.1590 / 0104-4060.48230$

1 Universidade Federal do Ceará. Fortaleza, Ceará, Brasil. Avenida da Universidade, nº 2853. Bairro: Benfica.CEP: 60020-180.E-mails: w_andriola@ufc.br e contabeisfeaac@yahoo.com.br 
strategy points trends, gaps, saturation spaces, the most recursive methods, reference works, among many other aspects of the research and scientific production from that. Thus, this study aimed to analyze demographic and methodological characteristics of theses and dissertations produced in Brazil about the program One Laptop per Student (PROUCA). Methodologically the study was descriptive and used the documentary procedure, with the content analysis of 43 theses and dissertations published in the period 2008-2014. The results showed: (a) apex of scientific work on the PROUCA between 2012 and 2013; (b) high concentration of researches in the southern and southeastern regions; (c) prevalence of case studies and (d) the majority employment of national bibliographic references.

Keywords: Information and Communication Technology (ICT); evaluation of social programs; educational technology.

\section{Introdução}

A análise da produção científica é relevante em qualquer área de conhecimento, uma vez que permite a identificação dos temas já estudados, bem como aqueles que necessitam de exploração. Ademais, possibilita reflexão sobre outros elementos importantes do estado da arte, tais como as revisões de teorias e as definições de políticas, científicas e tecnológicas. Esse tipo de investigação pode indicar necessidades de pesquisas futuras e tende a contribuir com a delimitação dos problemas que servirão para outros estudos. (NORONHA et al., 2006).

De acordo com Maculan e Lima (2011) a comunicação científica permite perceber o fluxo informacional e as diferentes abordagens teóricas, epistemológicas e práticas que caracterizam uma área do conhecimento. Além disso, possibilita aumento da visibilidade intelectual, legitimando e promovendo maior prestígio, o qual contribui, sobretudo, para a aquisição de financiamentos para suas atividades científicas.

Dos Santos e Kobashi (2009) afirmam que no início do século XXI, as técnicas de visualização de informação, em apoio aos métodos e técnicas de tratamento e análise de informação, passaram a ser utilizadas de forma vigorosa e recorrente. Com efeito, é possível fazer múltiplas inferências sobre os fatos que ocorrem na pesquisa científica a partir da análise de conteúdo dos documentos produzidos na academia (artigos, relatórios, teses e dissertações, entre outros). Nesse sentido, Witter (1999) pondera que a observação do que já foi produzido deveria ser prática constante em todas as ciências, incluindo a Educação.

Para Joly et al. (2010), nessa perspectiva, é de interesse analisar dissertações de mestrado e teses de doutorado por possibilitar a caracterização 
da produção científica das diferentes áreas do conhecimento. Por isso, esta investigação procurou analisar teses de doutorado e dissertações de mestrados defendidas e publicadas até fevereiro de 2015, disponíveis no Banco de Teses da Coordenação de Aperfeiçoamento de Pessoal de Nível Superior (CAPES) e na Biblioteca Digital Brasileira de Teses e Dissertações (BDTD).

\section{O Programa Um Computador Por Aluno (PROUCA): breve descrição}

Conforme Fabris e Finco (2012), o PROUCA tem como objetivo ser um projeto educacional de uso da TDIC como forma de promover inovações pedagógicas no ensino, mas também promover a inclusão digital. Outra meta do programa é proporcionar o adensamento da cadeia produtiva comercial no Brasil. A ideia de implantação desse programa no Brasil está relacionada com as iniciativas da organização não governamental internacional One Laptop per Child (OLPC), criada em 2005. Trata-se de um projeto promovido por uma fundação sem fins lucrativos, que se propõe desenvolver, produzir e distribuir laptops de baixo custo, com configurações diferenciadas e específicas, a alunos de países em desenvolvimento, para uso na modalidade 1:1, isto é, um computador para cada indivíduo. (BORGES; SANTOS, 2008).

O projeto OLPC foi criado por pesquisadores do Massachusetts Institute of Technology (MIT) liderados por Nicholas Negroponte. A ideia era projetar, fabricar e distribuir laptop a custos reduzidos com fins educacionais (denominado laptop $\mathrm{XO}$ ou, simplesmente, $\mathrm{XO}$ ) buscando garantir que um maior número de alunos da escola pública tivesse acesso à TDIC. (SOUZA; FERRETE, 2011; CANAL et al., 2011). Em pouco mais de três anos após a sua criação, o projeto obteve alcance mundial, abrangendo diversos países, especialmente da América Latina, África e Ásia, dentre eles o Brasil.

O Brasil teve o primeiro contato com a ideia por ocasião do Fórum Econômico Mundial de Davos na Suíça, em janeiro de 2005. (FABRIS; FINCO, 2012; ALMEIDA; PRADO, 2011). Em junho de 2005, Nicholas Negroponte, Seymour Papert e Mary Lou Jepsen vieram ao Brasil para expor a ideia ao governo federal brasileiro. (FABRIS; FINCO, 2012; ALMEIDA; PRADO, 2011; SOUZA; FERRETE, 2011). Nesse mesmo ano foi instituído grupo interministerial envolvendo os Ministérios da Educação e da Ciência e Tecnologia, incumbido de avaliar os aspectos técnicos e pedagógicos da proposta da OLPC. 
Durante 2007 foram iniciados experimentos do PROUCA em cinco escolas brasileiras nos estados de São Paulo, Rio Grande do Sul, Distrito Federal, Tocantins e Rio de Janeiro. Para tal, a então Secretaria de Educação a Distância do Ministério da Educação (SEED/MEC) fez várias sondagens a estados e municípios, buscando estabelecer parcerias que permitissem a adesão desses entes. (PORTAL UCA, 2014b).

A estrutura de formação, acompanhamento e avaliação do programa envolveu universidades que compuseram um grupo de trabalho e assessoramento pedagógico (GTUCA), segmentadas em "IES Global" e "IES Local". Segundo MEC (2010) as universidades IES-UCA-Global assumiram a preparação da IES-Local que, por sua vez, ficaram responsáveis por efetuar a formação dos profissionais do Núcleo de Tecnologia Educacional (NTE), o acompanhamento e a orientação desses nas escolas.

Em dezembro de 2009 o governo lançou a Medida Provisória 472/09 que criou institucionalmente o Programa Um Computador por Aluno (PROUCA), tendo sido convertida, em junho de 2010, na Lei $n^{\circ} 12.249 / 2009$. Ao ganhar o status de programa, o PROUCA entrou em sua segunda fase, denominada Fase II ou Fase Piloto, com a distribuição de 150.000 laptops educacionais em 300 escolas públicas pertencentes às redes de ensino estaduais e municipais. (MENESES, 2011; CYSNEIROS; CARVALHO; PANERAI, 2011).

Contudo, propor uma ação nas dimensões do programa UCA implica na ressignificação da escola. As unidades escolares contempladas com o programa deveriam passar por melhorias físicas, adquirir mobiliário novo e ter assegurado acesso à internet sem fio. (CAVALCANTE; NASCIMENTO; CASTRO FILHO, 2011; ALMEIDA; PRADO, 2011). Por outro lado, programas dessa natureza criam uma expectativa de transformações na cultura de produção e apropriação de saberes. Sob essa perspectiva Valente (2011) alerta que não adianta procurar música no piano, pois ela não está lá, assim como as ideias não estão nos computadores, mas na cabeça dos usuários. Portanto, somente implantar ou prover acesso aos computadores ou laptops não vai alterar a maneira como a educação é desenvolvida. Convém realçar que o presente estudo centrou-se na busca bibliográfica de teses e dissertações produzidas no Brasil, que se debruçaram sobre o Programa Um Computador Por Aluno (PROUCA).

\section{Metodologia}

O estudo apresenta-se como descritivo, com abordagem quali-quantitativa e emprego de procedimentos bibliográfico e documental. Na concepção de Gil 
(1999), a pesquisa descritiva procura descrever características de determinada população ou fenômeno, estabelecendo relações entre variáveis.

\section{Procedimentos}

Fez-se busca documental de teses e dissertações cujas temáticas mantivessem relação com o uso de laptops educacionais no PROUCA, em dois portais eletrônicos nacionais: o Banco de Teses da CAPES e a Biblioteca Digital Brasileira de Teses e Dissertações (BDTD). Como resultado, foram identificadas 43 pesquisas publicadas entre 2008 e 2014, que terminaram por compor o recorte deste estudo. O levantamento bibliográfico foi realizado entre janeiro e fevereiro de 2015, empregando-se como termos de busca as expressões "Um Computador Por Aluno", "Programa Um Computador Por Aluno", "Projeto Um Computador Por Aluno", "PROUCA", "UCA", "UCA Total”, "laptop educacional", "modalidade 1:1".

\section{Análise de resultados}

No total, foram identificados 40 trabalhos acadêmicos enfocando pesquisas sobre o PROUCA, sendo 10 teses (23\% do total) e 33 dissertações ( $77 \%$ do total). Entretanto, cumpre destacar que o arquivo completo de uma das dissertações não foi encontrado nos endereços eletrônicos disponíveis na BDTD e no Banco de Teses da CAPES. Contudo, o Banco de Teses da CAPES disponibilizou dados relativos ao tema, orientador, data de defesa, programa de pós-graduação e o resumo dessa. Observou-se predominância feminina quanto à autoria dos trabalhos sobre o PROUCA (76,7\% das dissertações). Outro fato que chamou a atenção diz respeito à distribuição das pesquisas por ano de defesa, conforme a Tabela 1 .

Os dados revelam que as primeiras dissertações sobre o PROUCA foram defendidas publicamente em 2008, enquanto a defesa da primeira tese ocorreu em 2011. Esse decurso temporal é coerente com o surgimento do PROUCA, cujas primeiras ações foram implementadas em 2007. Chama a atenção a concentração de pesquisas entre 2012-2013 ( $\mathrm{n}=22$ ou 51,2\% do total), embora 2014 tenha registrado maior número de teses $(n=9$ ou $27,3 \%)$.

Foram encontradas produções acadêmicas em 19 programas de Pós-Graduação de 19 Instituições de Ensino Superior (IES) das regiões Sul, Sudeste, Centro-Oeste e Nordeste. Observou-se forte concentração (n=30 ou 70\%) em 
ANDRIOLA, W. B.; GOMES, C. A. S. Programa Um Computador Por Aluno (PROUCA)...

TABELA 1 - DISTRIBUIÇÃO DAS TESES E DISSERTAÇÕES POR ANO DE DEFESA

\begin{tabular}{ccccccc}
\hline & \multicolumn{2}{c}{ Teses } & \multicolumn{2}{c}{ Dissertações } & \multicolumn{2}{c}{ Total } \\
\cline { 2 - 7 } Ano & $\mathrm{F}$ & $F$ & $\mathrm{~F}$ & $F$ & $\mathrm{~F}$ & $F$ \\
\hline 2008 & 0 & $0,0 \%$ & 3 & $9,1 \%$ & 3 & $7,0 \%$ \\
\hline 2009 & 0 & $0,0 \%$ & 5 & $15,2 \%$ & 5 & $11,6 \%$ \\
\hline 2010 & 0 & $0,0 \%$ & 2 & $6,0 \%$ & 2 & $4,7 \%$ \\
\hline 2011 & 1 & $10,0 \%$ & 3 & $9,1 \%$ & 4 & $9,3 \%$ \\
\hline 2012 & 3 & $30,0 \%$ & 8 & $24,2 \%$ & 11 & $25,6 \%$ \\
\hline 2013 & 2 & $20,0 \%$ & 9 & $27,3 \%$ & 11 & $25,6 \%$ \\
\hline 2014 & 4 & $40,0 \%$ & 3 & $9,1 \%$ & 7 & $16,2 \%$ \\
\hline TOTAL & $\mathbf{1 0}$ & $\mathbf{1 0 0} \%$ & $\mathbf{3 3}$ & $\mathbf{1 0 0 , 0} \%$ & $\mathbf{4 3}$ & $\mathbf{1 0 0 , 0} \%$ \\
\hline
\end{tabular}

FONTE: Os autores (2016).

seis delas (UFRGS, PUC-SP, UnB, UDESC, UFC e UERJ). Por outro lado, tão somente cinco estados brasileiros (RS, SP, DF, SC e CE) concentram $81,4 \%$ das teses e dissertações analisadas $(n=35)$.

No que diz respeito ao tipo de IES, observou-se que $86 \%$ das produções acadêmicas foram realizados em IES públicas $(n=37)$ e $34 \%$ em IES privadas $(\mathrm{n}=6)$. Ressalte-se que, dentre as públicas, houve predominância de federais ( $\mathrm{n}$ $=38$ ou $89 \%$ ) ante estaduais ( $\mathrm{n}=5$ ou $11 \%$ ). A maioria das pesquisas é oriunda de mestrado $(\mathrm{n}=28$ ou $85 \%)$ e doutorado $(\mathrm{n}=7$ ou $70 \%)$ em Educação, abordando diversidade de temas, conforme a Tabela 2.

TABELA 2 - ÁREAS TEMÁTICAS DAS PESQUISAS SOBRE O PROUCA

\begin{tabular}{lcccccc}
\hline \multirow{2}{*}{ Categorias } & \multicolumn{2}{c}{ Teses } & \multicolumn{2}{c}{ Dissertações } & \multicolumn{2}{c}{ Total } \\
\cline { 2 - 7 } & $\mathrm{F}$ & $f$ & $\mathrm{~F}$ & $f$ & $\mathrm{~F}$ & $F$ \\
\hline Processo de Ensino/Aprendizagem & 2 & $20,0 \%$ & 9 & $27,2 \%$ & 11 & $25,6 \%$ \\
\hline Prática docente & 0 & $0,0 \%$ & 8 & $24,2 \%$ & 8 & $18,6 \%$ \\
\hline Formação de professores & 3 & $30,0 \%$ & 2 & $6,1 \%$ & 5 & $11,6 \%$ \\
\hline Tecnologias digitais na educação & 2 & $20,0 \%$ & 3 & $9,1 \%$ & 5 & $11,6 \%$ \\
\hline Inclusão digital & 1 & $10,0 \%$ & 2 & $6,1 \%$ & 3 & $7,0 \%$ \\
\hline Implantação do UCA & 0 & $0,0 \%$ & 3 & $9,1 \%$ & 3 & $7,0 \%$ \\
\hline Currículo & 1 & $10,0 \%$ & 1 & $3,0 \%$ & 2 & $4,7 \%$ \\
\hline Educação inclusiva & 0 & $0,0 \%$ & 2 & $6,1 \%$ & 2 & $4,7 \%$ \\
\hline Outros & 1 & $10,0 \%$ & 3 & $9,1 \%$ & 4 & $9,2 \%$ \\
\hline & $\mathbf{1 0}$ & $\mathbf{1 0 0 , 0} \%$ & $\mathbf{3 3}$ & $\mathbf{1 0 0 , 0} \%$ & $\mathbf{4 3}$ & $\mathbf{1 0 0 , 0 \%}$ \\
\hline
\end{tabular}

FONTE: Os autores (2016). 
A temática Formação de Professores foi a de maior interesse entre as teses ( $\mathrm{n}=3$ ou $30 \%$ ), ao passo que Processo de Ensino/Aprendizagem obteve maior recorrência entre as dissertações ( $\mathrm{n}=9$ ou $27,2 \%)$. Considerando os dados conjuntos, observa-se que $67,8 \%$ das pesquisas $(\mathrm{n}=29)$ envolveram as temáticas Processo de Ensino/Aprendizagem, Prática Docente, Formação de Professores e Tecnologias Digitais na Educação.

Foram observados que nas dissertações os estudos de caso procuraram compreender de que maneira o laptop educacional influenciava o processo de ensino/aprendizagem e a prática dos professores nas escolas. Os pesquisadores demonstraram preocupação em relatar como essa experiência estava se dando nas escolas, descrevendo dificuldades e potencialidades. A formação dos professores foi objeto recorrente de interesse dos pesquisadores, especialmente entre as teses, haja vista essa ter sido a categoria individualmente mais representativa. Tais acepções ficam evidenciadas de modo mais explícito, com as informações descritivas nos Quadros 1 e 2, que apresentam os principais achados das pesquisas, bem como a sua autoria, ano de publicação e IES relacionada.

QUADRO 1 - TESES DE DOUTORADO SOBRE O USO DE LAPTOPS INDIVIDUAIS NA ESCOLA

\begin{tabular}{|c|l|}
\hline \multicolumn{1}{|c|}{ AUTOR/ANO/IES/TEMA } & \multicolumn{1}{c|}{ ACHADOS DA PESQUISA } \\
\hline $\begin{array}{l}\text { HOFFMANN (2011)/ UFRGS } \\
\text { Modalidade 1:1: tecnologia } \\
\text { individual possibilitando redes de } \\
\text { fluência digital. }\end{array}$ & $\begin{array}{l}\text { Desenvolveu uma pesquisa com dez estudantes de uma escola } \\
\text { participante do PROUCA do Rio Grande do Sul, a partir de todos } \\
\text { os arquivos armazenados no laptop educacional de modo a iden- } \\
\text { tificar a formaçao de uma Rede de fluência digital. Ela observou } \\
\text { que o número de arquivos de leitura foi superior aos arquivos de } \\
\text { edição e que a prática de exploração da internet foi concentrada na } \\
\text { busca e seleção de informações (e posterior organização e arma- } \\
\text { zenamento de materiais no laptop, esse último em menor propor- } \\
\text { ção). Observou também que o uso individual da tecnologia não } \\
\text { foi o mote principal do UCA e que a tecnologia individualmente } \\
\text { disponível tornou-se um meio agregador e não individualizante, } \\
\text { possibilitanto a constituição de uma rede digital. }\end{array}$ \\
\hline $\begin{array}{l}\text { PIORINO (2012) / PUC-SP } \\
\text { formação do professor e o de- } \\
\text { senvolvimento de competências } \\
\text { pedagógico-digitais: experiência } \\
\text { em escola pública que participa do } \\
\text { Projeto UCA. }\end{array}$ & $\begin{array}{l}\text { Analisou o processo de formação de professores de uma escola } \\
\text { participante do PROUCA de São Paulo com o olhar sobre o de- } \\
\text { senvolvimento de competências pedagógico-digitais e verificou } \\
\text { que foi necessário efetuar alterações no processo de formação de } \\
\text { modo a atender ao perfil da turma e o modo de aprender de cada } \\
\text { professor. Identificou problemas de infraestrutura (rede elétrica e } \\
\text { de internet, espaço físico para guarda dos laptops). Observou tam- } \\
\text { bém que as brechas digitais entre alunos e professores diminuem. }\end{array}$ \\
\hline
\end{tabular}

(Continua) 
(Continuação)

\begin{tabular}{|c|c|}
\hline AUTOR/ANO/IES/TEMA & ACHADOS DA PESQUISA \\
\hline $\begin{array}{l}\text { SARIAN (2012) / UNICAMP } \\
\text { A injunção ao novo e a repetição } \\
\text { do velho: um olhar discursivo ao } \\
\text { Programa Um Computador Por } \\
\text { Aluno (PROUCA). }\end{array}$ & $\begin{array}{l}\text { A pesquisa compreende o PROUCA filiado a uma concepção de } \\
\text { educação neoliberal, dessa forma a autora aponta que o Estado } \\
\text { inseriu o PROUCA num discurso no âmbito da inovação, da atu- } \\
\text { alização e da modernização e na produção de uma discursividade } \\
\text { sustentada pela ideia de novo, à medida que leva, para a escola } \\
\text { pública, o laptop com internet. Para a autora o funcionamento do } \\
\text { PROUCA ocorre como uma injunção ao preenchimento de uma } \\
\text { falta, construída historicamente, para a escolarização no Brasil. }\end{array}$ \\
\hline $\begin{array}{l}\text { TEIXEIRA (2012) / UFMG } \\
\text { Difusão tecnológica no ensino de } \\
\text { línguas: o uso de computadores } \\
\text { portáteis nas aulas de língua por- } \\
\text { tuguesa sob a ótica da complexi- } \\
\text { dade. }\end{array}$ & $\begin{array}{l}\text { A pesquisa defende que no caso do PROUCA, a implementação } \\
\text { do projeto e sua difusão não são baseadas apenas em agentes } \\
\text { multiplicadores; há a preocupação com a interação entre diversos } \\
\text { agentes de diferentes níveis, contudo o recebimento dos laptops } \\
\text { foi imposto aos docentes, bem como o número mínimo de vezes } \\
\text { que deveriam utilizá-los em sala de aula. A capacitação dada, tanto } \\
\text { presencial quanto à distância, foi considerada, pela grande maioria } \\
\text { dos docentes, como insuficiente. A utilização do equipamento de } \\
\text { modo compulsório gerou turbulências no sistema da sala de aula } \\
\text { e do próprio docente. Essas turbulências ocasionaram fases de bi- } \\
\text { furcação, em que cada docente questionou como usar o aparelho } \\
\text { e por que. A investigação percebeu que, para alguns docentes, a } \\
\text { tecnologia foi incorporada à sua prática, mas, para outros, ela ain- } \\
\text { da não tem significado. Não houve percepção de ganho real com o } \\
\text { seu uso e, nos momentos em que o equipamento falha, o docente } \\
\text { sempre retoma o seu modo anterior de ensinar. }\end{array}$ \\
\hline $\begin{array}{l}\text { SILVA (2013) / PUCSP } \\
\text { Comunidades de prática online: } \\
\text { contribuições à formação de pro- } \\
\text { fessores no Brasil e em Portugal. }\end{array}$ & $\begin{array}{l}\text { A pesquisa procurou analisar quais indicadores de potencial das } \\
\text { Comunidade de Prática Online (COP) no Brasil e em Portugal } \\
\text { contribuíram para a formação compartilhada dos professores no } \\
\text { desenvolvimento de competências pedagógicas como o uso de } \\
\text { tecnologias digitais dentro do PROUCA e a partir da experiência } \\
\text { de uma escola do estado de São Paulo identificou que o comparti- } \\
\text { lhamento de experiências em uma COP permitiu construir conhe- } \\
\text { cimentos sobre a integração de tecnologias digitais no contexto } \\
\text { educacional e que os participantes passaram a compreender me- } \\
\text { lhor o seu papel enquanto agente de mudança que planifica e refle- } \\
\text { te sobre suas ações pedagógicas em sala de aula. }\end{array}$ \\
\hline $\begin{array}{l}\text { CASARIN (2014) / UFRGS } \\
\text { O programa um computador por } \\
\text { aluno (PROUCA) e a inclusão de } \\
\text { alunos com deficiência. }\end{array}$ & $\begin{array}{l}\text { Estudou o PROUCA sob a ótica da educação inclusiva tomando } \\
\text { por base alunos de uma escola participante do programa. Obser- } \\
\text { vou dificuldades no processo de inclusão digital, social e educa- } \\
\text { cional motivadas por problemas relativos à mobilidade (os alunos } \\
\text { não levam os laptops para casa e todas as aulas com o equipamen- } \\
\text { to ocorreram no laboratório de informática), constrangimento e } \\
\text { frustração a alguns alunos que não conseguem lidar com a tecno- } \\
\text { logia, baixa frequência de uso dos laptops (apenas uma vez por } \\
\text { semana), inexistência de um projeto pedagógico que valorize a } \\
\text { tecnologia PROUCA na escola (deixando de fomentar condições } \\
\text { para o aprender e o incluir) e inadequação da estrutura física da es- } \\
\text { cola (espaço físico das salas, quantidade insuficiente de tomadas, } \\
\text { sinal de internet instável). }\end{array}$ \\
\hline
\end{tabular}

(Continua) 
(Conclusão)

\begin{tabular}{|c|c|}
\hline AUTOR/ANO/IES/TEMA & ACHADOS DA PESQUISA \\
\hline \begin{tabular}{l}
\multicolumn{1}{c}{ SILVA (2014) / UFRGS } \\
Formação continuada de profes- \\
sores para o Projeto UCA: análise \\
dos processos formativos prescri- \\
tos, vivenciados e narrados.
\end{tabular} & $\begin{array}{l}\text { Analisou o processo formativo prescrito, vivenciado e narrado na } \\
\text { formação dos professores de uma escola participante do PROUCA } \\
\text { no estado do Mato Grosso e verificou uma frustração nas expecta- } \\
\text { tivas, falta de motivação e precária inclusão digital de professores } \\
\text { e alunos da escola por consequência das problemáticas condições } \\
\text { de infraestrutura física e logística da escola, da sobrecarga e frag- } \\
\text { mentação do trabalho docente e do distanciamento da proposta de } \\
\text { formação em comparação com as reais necessidades dos professo- } \\
\text { res. Os laptops educacionais foram usados na mesma perspectiva } \\
\text { dos livros didáticos, de enciclopédias e dicionário e também para } \\
\text { acessar repositórios de conteúdos prontos na internet. }\end{array}$ \\
\hline $\begin{array}{l}\text { VELLOSO (2014) / UERJ } \\
\text { Das máquinas de ensinar aos } \\
\text { netbooks: tradição, inovação e tra- } \\
\text { dução. }\end{array}$ & $\begin{array}{l}\text { A investigação, de cunho etnográfico, foi efetivada por meio de } \\
\text { observação sistemática, conversas informais, entrevistas gravadas } \\
\text { e transcritas, fotografias, participação em atividades de uma escola } \\
\text { da rede municipal do Rio de Janeiro participante do PROUCA. } \\
\text { Segundo a autora, foi possível observar, no contato com a escola, } \\
\text { as dificuldades e estratégias desenvolvidas para colocar em prática } \\
\text { o equipamento, tanto pelos alunos, quanto pelos professores e os } \\
\text { problemas relacionados à produção de um currículo escolar que } \\
\text { atenda a uma política de resultados. }\end{array}$ \\
\hline $\begin{array}{l}\text { DE ALMEIDA (2014) / PUC-SP } \\
\text { Programa Um Computador Por } \\
\text { Aluno: as práticas pedagógi- } \\
\text { cas desenvolvidas com o uso do } \\
\text { laptop. }\end{array}$ & $\begin{array}{l}\text { O estudo investigou as práticas pedagógicas dos professores com } \\
\text { o uso do laptop educacional em sala de aula e procurou também } \\
\text { conhecer o modo como os equipamentos são integrados ao coti- } \\
\text { diano escolar e quais práticas surgem a partir do seu uso. A pesqui- } \\
\text { sa mostrou também a maneira como o projeto foi implementado e } \\
\text { suas influências na prática pedagógica, bem como o processo de } \\
\text { apropriação, pelos professores, dos recursos do laptop educacio- } \\
\text { nal, e a sua inserção nas atividades em sala de aula. A pesquisa } \\
\text { apontou que os professores trabalham com o erro de forma cons- } \\
\text { trutivista, entendendo-o como parte do processo de aprendizagem } \\
\text { e em determinadas situações a tecnologia favorece a uma relação } \\
\text { de proximidade entre professor e aluno. }\end{array}$ \\
\hline
\end{tabular}

FONTE: Os autores (2016).

Entre as teses, observou-se diversidade na concepção dos temas de pesquisa dada a ocorrência de sete das nove categorias catalogadas. Os estudos evidenciam as potencialidades do PROUCA, mas apontam falhas no processo de implantação, formação, apropriação tecnológica e uso pedagógico do laptop educacional. 


\section{QUADRO 2 - DISSERTAÇÕES DE MESTRADO SOBRE O USO DE LAPTOPS INDIVI- DUAIS NA ESCOLA}

\begin{tabular}{|c|c|}
\hline AUTOR/ANO/IES/TEMA & ACHADOS DA PESQUISA \\
\hline $\begin{array}{l}\text { SCHAFER (2008) / UFRGS } \\
\text { O percurso das enunciações em } \\
\text { projetos de aprendizagem na mo- } \\
\text { dalidade } 1: 1 .\end{array}$ & $\begin{array}{l}\text { A pesquisa foi construída a partir do contexto da proposta meto- } \\
\text { dológica de Projetos de Aprendizagem, numa escola da fase pré- } \\
\text {-piloto localizada em Porto Alegre, e identificou a inexistência de } \\
\text { vínculo pré-determinado entre a escrita e a compreensão sobre o } \\
\text { registro textual realizadas pelo aluno mesmo com a presença dos } \\
\text { laptops, a autora reconhece, contudo, que a apropriação, a mobili- } \\
\text { dade e a disponibilidade diária de computadores propiciam ao alu- } \\
\text { no a possibilidade de uma produção constante e passível de maior } \\
\text { visibilidade, assim como viabilizam ao professor a realização de } \\
\text { um acompanhamento mais sistemático dessa produção. }\end{array}$ \\
\hline $\begin{array}{c}\text { KIST (2008) / UFRGS } \\
\text { Laptop por criança: implicações } \\
\text { para as práticas de leitura e escrita. }\end{array}$ & $\begin{array}{l}\text { A pesquisadora estudou a prática de leitura de crianças de } 6 \text { anos } \\
\text { em uma escola de Porto Alegre imersas em um cotidiano digi- } \\
\text { tal (projeto UCA). Ela concluiu que a prática de leitura e escrita } \\
\text { alteram-se em um contexto de imersão num cotidiano digital, pois } \\
\text { essa oportuniza a inclusão no mundo virtual letrado, ampliando } \\
\text { as possibilidades de engajamento social, porém, tais resultados se } \\
\text { manifestam sob determinadas condições tais como, a disponibili- } \\
\text { dade da professora para experimentar e inventar uma proposta de } \\
\text { uso do laptop em sala de aula, o uso do ambiente na web para pu- } \\
\text { blicar/registrar/compartilhar as produções, o trabalho por projetos } \\
\text { que criou o contexto e o sentido para que muitas práticas como o } \\
\text { uso do laptop acontecessem, a adequada conexão com a internet } \\
\text { dentro e fora da sala de aula e a formação que abriu possibilidades } \\
\text { para as propostas da professora. }\end{array}$ \\
\hline $\begin{array}{l}\text { CAMBOIM (2008) / UNB } \\
\text { Cadê o computador que estava } \\
\text { aqui? As relações de poder e sua } \\
\text { influência na compra dos laptops } \\
\text { educacionais no governo Lula da } \\
\text { Silva. }\end{array}$ & $\begin{array}{l}\text { Por meio da observação e da análise de conteúdo (e contexto) de } \\
468 \text { e-mails da lista de discussões OLPC-Brasil, a autora obser- } \\
\text { vou que, conforme o discurso pedagógico e as relações de poder } \\
\text { que envolviam a compra dos laptops educacionais, havia naquele } \\
\text { momento, fortes indícios de que existira um modelo específico de } \\
\text { laptop educacional que estava sendo oferecido ao governo bra- } \\
\text { sileiro, o X0 da OLPC, uma vez que os assuntos relacionados à } \\
\text { melhoria da infraestrutura das escolas e à qualificação dos profes- } \\
\text { sores pautaram apenas } 0,71 \% \text { e } 10 \% \text { dos assuntos tratados na lista. }\end{array}$ \\
\hline $\begin{array}{l}\text { MENDES (2009) / PUC-SP } \\
\text { Introdução do laptop educacional } \\
\text { em sala de aula: indícios de } \\
\text { mudanças na organização e gestão } \\
\text { da aula. }\end{array}$ & $\begin{array}{l}\text { A pesquisa ocorreu em uma escola participante do PROUCA da } \\
\text { cidade de Palmas (TO) e identificou que a presença dos laptops } \\
\text { educacionais em sala de aula trouxe alterações na dinâmica da } \\
\text { aula e que os alunos ficaram bastante à vontade com o uso do } \\
\text { equipamento, dentre e fora da sala. A pesquisa sugeriu que houve } \\
\text { melhoria na média geral de notas das turmas que utilizaram os lap- } \\
\text { tops entre os anos de } 2006 \text { e } 2007 \text { e que os professores precisaram } \\
\text { encontrar novas formas de gerir aula que envolve mudanças tanto } \\
\text { no planejamento das aulas como na prática pedagógica. }\end{array}$ \\
\hline
\end{tabular}


(Continuação)

\begin{tabular}{|c|c|}
\hline AUTOR/ANO/IES/TEMA & ACHADOS DA PESQUISA \\
\hline $\begin{array}{l}\text { MASCARENHAS (2009) / UNB } \\
\text { Inclusão digital dos alunos do } \\
\text { Colégio Dom Alano Marie Du } \\
\text { Noday: o projeto UCA em Palmas } \\
\text { (TO). }\end{array}$ & $\begin{array}{l}\text { Os resultados desta pesquisa mostram que, dos três indicadores de } \\
\text { inclusão digital (acesso às tecnologias, capacidade para manejá-las } \\
\text { e capacidade de integrá-las aos afazeres cotidianos) os dois primei- } \\
\text { ros foram alcançados satisfatoriamente, mas o terceiro, apontado } \\
\text { no estudo como o mais importante, não atingiu o mesmo patamar, } \\
\text { e isso implica que o processo de inclusão digital não alcançou sua } \\
\text { plenitude entre os envolvidos da pesquisa no Projeto UCA }\end{array}$ \\
\hline $\begin{array}{l}\text { MARQUES (2009) / UFPR } \\
\text { O projeto Um Computador Por } \\
\text { Aluno (UCA): Relações na escola, } \\
\text { professores, alunos, institucional. }\end{array}$ & $\begin{array}{l}\text { O estudo mostrou, por meio da análise de discurso de um grupo } \\
\text { de professores e alunos de uma escola atendida pelo então Projeto } \\
\text { UCA (fase Pré-piloto), que existe uma convergência entre a teoria } \\
\text { e a prática apresentada, ou seja, as opiniões de alunos e professo- } \\
\text { res apontam para uma realidade nada animadora: a formação dos } \\
\text { professores para o uso das tecnologias de informação e comunica- } \\
\text { ção, especialmente o Projeto UCA, ainda é deficiente. Ficou claro, } \\
\text { assim, que a formação dos professores na prática não se concre- } \\
\text { tiza, pois eles têm despreparo profissional e falta de um projeto } \\
\text { pedagógico que possa facilitar o uso do computador. }\end{array}$ \\
\hline $\begin{array}{l}\text { DA SILVA (2009b) / PUC-SP } \\
\text { O impacto inicial do laptop edu- } \\
\text { cacional no olhar de professores } \\
\text { da Rede Pública de Ensino. }\end{array}$ & $\begin{array}{l}\text { O estudo realizou um levantamento das primeiras impressões de } \\
\text { um grupo de professores da educação básica da rede pública sobre } \\
\text { o uso do laptop educacional na escola. A pesquisa identificou que } \\
\text { as categorias mobilidade e mudança da prática pedagógica foram } \\
\text { apontadas pelos professores em todo o percurso da pesquisa, de } \\
\text { mesmo modo em que eles demonstraram boa aceitação dos lap- } \\
\text { tops pelo seu potencial pedagógico e na escola, o uso do laptop } \\
\text { favoreceu a relação professor/alunos e aluno/aluno, favorecendo o } \\
\text { comprometimento dos alunos com as aulas. }\end{array}$ \\
\hline $\begin{array}{l}\text { DA SILVA (2009a) / UNB } \\
\text { Repercussões do Projeto um } \\
\text { computador por aluno no Colégio } \\
\text { Estadual Dom Alano Marie Du } \\
\text { Noday (TO). }\end{array}$ & $\begin{array}{l}\text { O estudo abordou as repercussões do então Projeto UCA em uma } \\
\text { escola no município de Palmas (TO) a partir de dados coletados } \\
\text { junto a coordenadores pedagógicos, professores e alunos e iden- } \\
\text { tificou que houve mudança na organização do trabalho pedagó- } \\
\text { gico a partir da presença do laptop educacional em sala de aula, } \\
\text { especialmente no tocante à dinamicidade das aulas e da interação } \\
\text { entre professor/aluno e aluno/aluno. Foram identificadas, porém, } \\
\text { dificuldades na sistematização dos processos que envolvem o pla- } \\
\text { nejamento didático. }\end{array}$ \\
\hline $\begin{array}{l}\text { MOREIRA (2010) / UNB } \\
\text { Análise de reações de professores } \\
\text { face à introdução do computador } \\
\text { na educação: o caso do projeto } \\
\text {-UCA - um computador por aluno } \\
\text { no Colégio Estadual Dom Alano } \\
\text { Marie Du Noday (TO). }\end{array}$ & $\begin{array}{l}\text { A investigação mostrou uma mudança significativa nas reações } \\
\text { dos professores com a utilização dos laptops educacionais na } \\
\text { sala de aula. O estudo identificou, nas falas dos sujeitos partici- } \\
\text { pantes da pesquisa, momentos de interação na relação educativa } \\
\text { entre professores e alunos por meio da troca de conhecimentos } \\
\text { mediados pelos recursos tecnológicos, especialmente, os disponi- } \\
\text { bilizados nos ambientes virtuais. Os resultados apontam para um } \\
\text { processo de adoção parcial da inovação caracterizada pelo uso do } \\
\text { computador nas ações pedagógicas e a adoção não se dá de forma } \\
\text { plena em razão de problemas relacionados à estrutura física e ao } \\
\text { suporte técnico-pedagógico, fatores apontados como dificultado- } \\
\text { res no processo de adesão à inovação. }\end{array}$ \\
\hline
\end{tabular}

(Continua) 
(Continuação)

\begin{tabular}{|c|c|}
\hline AUTOR/ANO/IES/TEMA & ACHADOS DA PESQUISA \\
\hline $\begin{array}{l}\text { DOS SANTOS (2010) / UDESC } \\
\text { Laptops na escola: mudanças e } \\
\text { permanências no currículo. }\end{array}$ & $\begin{array}{l}\text { O estudo identificou, por meio da fala dos entrevistados da escola } \\
\text { pesquisada, a permanência no currículo prescrito da instituição, } \\
\text { apesar da ocorrência de uma mudança temporária na distribuição } \\
\text { da carga horária ao longo do ano letivo, mas enfatiza que a estrutura } \\
\text { curricular não foi oficialmente alterada. No entanto, também } \\
\text { foram percebidas mudanças no currículo em ação, tais como a } \\
\text { inserção de novas propostas de encaminhamentos pedagógicos } \\
\text { e a incorporação de informações relativas ao uso dos laptops } \\
\text { no cotidiano escolar. Ações essas resultantes da interação e das } \\
\text { possibilidades de acesso à informação que os laptops educacionais } \\
\text { oportunizaram à comunidade escolar. Tal panorama repercutiu em } \\
\text { novas práticas curriculares em sala de aula. }\end{array}$ \\
\hline \begin{tabular}{|l|}
\multicolumn{1}{|c|}{ XAVIER (2010) / UERJ } \\
O Programa Um Computador Por \\
Aluno e o Ensino de Geografia.
\end{tabular} & $\begin{array}{l}\text { A pesquisa observou que a escola pesquisada recebeu primeira- } \\
\text { mente a informatização móvel do PROUCA sem antes ter havido } \\
\text { contato com nenhum outro plano nacional de informática que pu- } \\
\text { desse constituir uma base para a realização práticas antecessoras. } \\
\text { Essa constatação se tornou importante porque que muitas das di- } \\
\text { ficuldades decorreptes foram justamente a falta de domínio das } \\
\text { tecnologias, em especial, no âmbito pedagógico. A infraestrutura } \\
\text { foi um empecilho em todas as experiências realizadas bem como } \\
\text { a estrutura em rede, condição básica para a mobilidade e acesso } \\
\text { a conteúdos diversos e diálogos interativos dos atores escolares } \\
\text { através do ciberespaço. Percebeu-se um descompasso entre o no } \\
\text { de usuários existentes na realização das experiências-pilotos e a } \\
\text { capacidade de suporte de usuários das redes telemáticas e sua res- } \\
\text { pectiva abrangência territorial. A carga de energia e o limitado no } \\
\text { de laptops em relação ao quantitativo de alunos se tornou uma } \\
\text { constante negativa, principalmente quando se realizava experiên- } \\
\text { cias a partir do compartilhamento de laptops por turmas ou turnos. }\end{array}$ \\
\hline \begin{tabular}{|l|} 
PONTES (2011) / UFC \\
O uso da Web 2.0 na educação: Um \\
estudo de caso com professores \\
participantes do Projeto Um \\
Computador Por Aluno (UCA).
\end{tabular} & $\begin{array}{l}\text { Os resultados da pesquisa apontaram que as professoras não co- } \\
\text { nheciam as possibilidades pedagógicas da Web } 2.0 \text {, mas que no } \\
\text { decorrer da investigação obtiveram mudanças positivas no uso } \\
\text { instrumental e pedagógico das ferramentas utilizadas, assim como } \\
\text { realizaram aulas experimentais nas quais estimularam os alunos } \\
\text { a interagirem e colaborarem em rede. Dentro desse contexto, o } \\
\text { Projeto UCA se mostrou como uma oportunidade para estimular } \\
\text { inovadoras práticas pedagógicas por meio da filosofia da Web } 2.0 \text {. } \\
\text { A autora aponta, contudo, que para que esses avanços continuem, } \\
\text { as professoras precisam dispor de mais tempo para se apropriar e } \\
\text { planejar aulas com as ferramentas da Web 2.0. }\end{array}$ \\
\hline \begin{tabular}{|l|}
\multicolumn{3}{|c|}{ ARAÚJO (2011) / UFAL } \\
Diagnóstico das condições de \\
implantação do Projeto Um \\
Computador por Aluno (UC) nas \\
Escolas Públicas de Alagoas.
\end{tabular} & $\begin{array}{l}\text { O estudo desenvolvido nas nove escolas participantes do PROU- } \\
\text { CA no estado de Alagoas envolveu } 9 \text { gestores, } 7 \text { coordenadores } \\
\text { pedagógicos, } 104 \text { professores e } 324 \text { alunos, e indicou que as esco- } \\
\text { las, em geral, não fazem uso de computadores em seu cotidiano, } \\
\text { mas que, no momento da pesquisa, existia uma expectativa muito } \\
\text { grande quanto à aprendizagem e integração das mídias no fazer } \\
\text { docente por parte de alunos, gestores e professores. }\end{array}$ \\
\hline
\end{tabular}

(Continua) 
(Continuação)

\begin{tabular}{|c|c|}
\hline AUTOR/ANO/IES/TEMA & ACHADOS DA PESQUISA \\
\hline $\begin{array}{l}\text { SCHNEIDER (2012) / UFRGS } \\
\text { Cidade Um Computador por Alu- } \\
\text { no - UCA Total: Uma totalidade } \\
\text { inclusiva em discussão. }\end{array}$ & $\begin{array}{l}\text { A pesquisa apontou que o PROUCA baliza a ferramenta (laptop } \\
\text { educacional) sob o conceito da homogeneidade e uniformidade } \\
\text { tecnológica e isso impõe barreiras ao atendimento da diversidade } \\
\text { em situação de inclusão sociodigital. Observou-se que a prática } \\
\text { inclusiva no município pesquisado, garante a vinculação do aluno } \\
\text { especial à rede regular de ensino, mas ainda não articula movi- } \\
\text { mentos capazes de promover a efetiva participação dos sujeitos } \\
\text { com deficiência no ambiente escolar, e o PROUCA não contribuiu } \\
\text { para a mudança desse quadro. }\end{array}$ \\
\hline \begin{tabular}{l}
\multicolumn{1}{|c|}{ RIGONI (2012) / UCS } \\
Laptop educacional: mecanismos \\
sociocognitivos nos contextos de \\
aprendizagem.
\end{tabular} & $\begin{array}{l}\text { A pesquisa concluiu que as possibilidades da interface física e di- } \\
\text { gital nos contextos de aprendizagem, considerando a mobilidade } \\
\text { do laptop na modalidade } 1: 1 \text {, podem configurar novas relações e } \\
\text { desafios no processo de ensino e aprendizagem. Com relação aos } \\
\text { mecanismos sociocognitivos, evidenciou-se uma tendência de re- } \\
\text { lações de conformismo e de coação nas trocas interindividuais e } \\
\text { um falso equilíbrio de cooperação. }\end{array}$ \\
\hline $\begin{array}{l}\text { PINTO (2012) / UNIT } \\
\text { Análise dos problemas e soluções } \\
\text { do sistema operacional Metasys } \\
\text { nos laptops do PROUCA no Colé- } \\
\text { gio de Aplicação da Universidade } \\
\text { Federal de Sergipe. }\end{array}$ & $\begin{array}{l}\text { Ao descrever a utilização, do sistema operacional instalado nos } \\
\text { laptops do Programa Um Computador por Aluno (PROUCA) no } \\
\text { Colégio de Aplicação da Universidade Federal de Sergipe (CO- } \\
\text { DAP), a análise dos dados apontou para uma necessidade de me- } \\
\text { lhor formação dos professores para o uso do Sistema Operacional } \\
\text { dos laptops bem como a elaboração de um tutorial que possa mos- } \\
\text { trar a resolução de alguns problemas apresentados pelo Metasys. }\end{array}$ \\
\hline $\begin{array}{l}\text { MACIEL (2012) / UFRGS } \\
\text { Um computador por aluno fora do } \\
\text { contexto escolar: cenas digitais do } \\
\text { Plan Ceibal na fronteira do Brasil } \\
\text { com Uruguai. }\end{array}$ & $\begin{array}{l}\text { O estudo foi realizado numa cidade do interior do Uruguai próxi- } \\
\text { mo à fronteira com o Brasil e efetuou o mapeamento dos espaços } \\
\text { de utilização dos computadores pelos alunos na comunidade. A } \\
\text { pesquisa aponta que os alunos fazem uso da tecnologia fora da } \\
\text { escola, trazendo novos sentidos para o uso, vinculando as práticas } \\
\text { culturais estabelecidas e não a capacidade tecnológica da tecnolo- } \\
\text { gia em si. Foram identificados também várias formas de socializa- } \\
\text { ção vinculadas ao uso dos computadores pelos alunos em espaços } \\
\text { públicos, confirmando que a tecnologia está sendo utilizada como } \\
\text { mais um componente do meio e que as produções a partir desse } \\
\text { uso moldam novas práticas na internet e fora dela na comunidade } \\
\text { estudada, caracterizando a tecnologia com cultura e como artefato } \\
\text { dessa cultura. }\end{array}$ \\
\hline \begin{tabular}{l}
\multicolumn{1}{|c|}{ FALCÃO (2012) / UNB } \\
Interações entre professores e alu- \\
nos em situação de ensino-apren- \\
dizagem mediadas por NTICE: \\
Retratos do Projeto UCA no Dis- \\
trito Federal (DF).
\end{tabular} & $\begin{array}{l}\text { O resultado desta investigação demonstra que o professor é o } \\
\text { principal elemento na condução de uma ação educativa eficaz no } \\
\text { que diz respeito à promoção da interatividade, encontrada a partir } \\
\text { de uma Interação Dinâmica, tão importante no processo de ensino- } \\
\text { aprendizagem. A pesquisa aponta também que entraves técnicos, } \\
\text { de estrutura mínima requerida para o funcionamento do programa } \\
\text { UCA, muitas vezes impedem a execução efetiva de uma atividade } \\
\text { pedagógica previamente planejada. }\end{array}$ \\
\hline
\end{tabular}

(Continua) 
(Continuação)

\begin{tabular}{|c|c|}
\hline AUTOR/ANO/IES/TEMA & ACHADOS DA PESQUISA \\
\hline $\begin{array}{l}\text { EIVAZIAN (2012) / UNIBAN } \\
\text { O Computador móvel e a prática } \\
\text { de professores que ensinam mate- } \\
\text { mática em uma escola do Projeto } \\
\text { UCA. }\end{array}$ & $\begin{array}{l}\text { A análise dos dados desta pesquisa mostra algumas tendências de } \\
\text { práticas com uso do laptop educacional nas aulas de matemáti- } \\
\text { ca, tais como, jogos educacionais, alguns softwares disponíveis } \\
\text { no computador e os recursos da internet, os quais permitem o } \\
\text { desenvolvimento de atividades relacionadas ao tratamento de in- } \\
\text { formações, buscas, comunicação e representações matemáticas. } \\
\text { Tais práticas também foram analisadas para verificar os níveis de } \\
\text { apropriação tecnológica e pedagógica dos professores, uma vez } \\
\text { que o entendimento desse processo de apropriação é fundamental } \\
\text { para que o professor possa avançar, tendo condições de fazer um } \\
\text { uso inovador do laptop educacional e, ao mesmo tempo, assegurar } \\
\text { o rigor conceitual da matemática. O estudo ressaltou também a } \\
\text { necessidade da formação do professor. }\end{array}$ \\
\hline $\begin{array}{l}\text { MARTINS (2012) / UNISINOS } \\
\text { O significado do fazer ciência } \\
\text { no contexto da cultura digital } \\
\text { emergente: um estudo em uma } \\
\text { escola da região metropolitana } \\
\text { de Porto Alegre participante do } \\
\text { PROUCA. }\end{array}$ & $\begin{array}{l}\text { A pesquisa identificou que no início do processo de formação dos } \\
\text { professores da escola PROUCA pesquisada, houve entusiasmo } \\
\text { dos mesmos diante da novidade representada pelos laptops edu- } \\
\text { cacionais, embora tenha-se observado também certa insegurança } \\
\text { na utilização da tecnologia disponibilizada. Constatou-se também } \\
\text { que o PROUCA colocou à disposição da escola uma tecnologia } \\
\text { que amplia o acesso às informaçôes e os professores entendem } \\
\text { essa tecnologia como uma composição entre o laptop e a internet } \\
\text { e que o "erro" não é trabalhado pelos professores, pois não consi- } \\
\text { deram imprevistos e nem a discrepância na análise dos resultados. }\end{array}$ \\
\hline $\begin{array}{l}\quad \text { REIS (2012) / PUC-MG } \\
\text { O uso 1:1 do laptop na educação } \\
\text { matemática: permanência e mu- } \\
\text { danças no ensino e na aprendiza- } \\
\text { gem. }\end{array}$ & $\begin{array}{l}\text { O estudo identificou algumas mudanças nas práticas pedagógicas } \\
\text { do professor quando do uso do laptop educacional, tais como o } \\
\text { surgimento de uma preocupação do professor com o planejamen- } \\
\text { to das aulas, com a necessidade de reorganizar e ressignificar o } \\
\text { currículo estabelecido, apontando indícios de construção de um } \\
\text { web currículo de Matemática. A pesquisa apontou, também, que } \\
\text { ainda existem alguns desafios a serem superados, tais como algu- } \\
\text { mas permanências de práticas tradicionais no ensino e na apren- } \\
\text { dizagem que se mantêm até pela necessidade de se cumprirem os } \\
\text { planos de curso e de preparar o aluno para os exames oficiais. Por } \\
\text { outro lado, observou a necessidade da formação do professor, na } \\
\text { perspectiva de que conheça novas ferramentas para a melhor inser- } \\
\text { ção do laptop educacional no currículo. }\end{array}$ \\
\hline $\begin{array}{l}\text { DOS SANTOS (2013) / UFOP } \\
\text { Entre o lápis, o papel e a tela: a } \\
\text { presença das TDIC nas práticas } \\
\text { de alfabetização e letramento em } \\
\text { escolas do Município de Tiraden- } \\
\text { tes - MG. }\end{array}$ & $\begin{array}{l}\text { A pesquisa inferiu que a utilização dos laptops educacionais e seus } \\
\text { recursos lúdicos e interativos acabaram por contribuir para o ensino } \\
\text { da língua materna em seu aspecto mecânico, no entanto, foi obser- } \\
\text { vado que o PROUCA necessita dispor de uma capacitação que en- } \\
\text { foque ações pedagógicas práticas, de modo a conferir um uso mais } \\
\text { significativo que suas interfaces permitem. A falta de suporte téc- } \\
\text { nico pedagógico, fruto da não vigência da política de manutenção, } \\
\text { auxilia e compõe aspectos lacunares do cenário. Os experimentos } \\
\text { com laptop apontaram que o software educacional MEA atende aos } \\
\text { aspectos mecânicos dos processos de alfabetização por meio de sua } \\
\text { interface lúdica e dos elementos próprios da multimídia, porém, a } \\
\text { ausência de continuidade na capacitação dos professores para sua } \\
\text { utilização e reconhecimento das demais propriedades sinaliza as } \\
\text { necessidades para que o uso se dê de forma mais efetiva. }\end{array}$ \\
\hline
\end{tabular}

(Continua) 
(Continuação)

\begin{tabular}{|c|c|}
\hline AUTOR/ANO/IES/TEMA & ACHADOS DA PESQUISA \\
\hline $\begin{array}{l}\text { ZANATTA (2013) / UDESC } \\
\text { Gestão e inovação educacional: } \\
\text { as tecnologias móveis no espaço } \\
\text { escolar. }\end{array}$ & $\begin{array}{l}\text { Com enfoque nas escolas PROUCA do estado de Santa Catarina, } \\
\text { a pesquisa identificou a partir dos depoimentos dos gestores que } \\
\text { o envolvimento da secretaria de Estado ou municipais é definiti- } \\
\text { vo no sucesso da inserção de propostas federais, pois essas são } \\
\text { responsáveis pela proposição e financiamento inicial, mas a im- } \\
\text { plementação está ligada à incorporação da política na dinâmica } \\
\text { do Estado e nos municípios. A pesquisa identificou também dife- } \\
\text { renças entre as escolas no que concerne à organização do progra- } \\
\text { ma (como, por exemplo, local de armazenamento das máquinas, } \\
\text { número de pontos de acesso à internet, uso de fibra ótica, dispo- } \\
\text { nibilidade de técnico de informática para atuar na escola, etc.) e } \\
\text { que houve muita mobilização dos gestores e diretores e equipes } \\
\text { pedagógicas, para buscarem recursos e concretizar a proposta de } \\
\text { inserção dos laptops nas suas escolas. }\end{array}$ \\
\hline $\begin{array}{l}\text { SPAGNOLO (2013) / UFRGS } \\
\text { Formação continuada de } \\
\text { professores e projeto PROUCA: } \\
\text { reflexões acerca do prazer em } \\
\text { ensinar apoiado por tecnologias } \\
\text { digitais. }\end{array}$ & $\begin{array}{l}\text { A pesquisa percebeu a preocupação dos docentes para o ato de } \\
\text { ensinar e aprender de maneira reflexiva, inovadora e qualitativa } \\
\text { pela inserção das tecnologias de informação e comunicação no co- } \\
\text { tidiano escolar. Os relatos apontam para mudanças significativas } \\
\text { na prática pedagógica, em razão das inúmeras possibilidades de } \\
\text { interação, apropriação e autoria nas práticas escolares com o uso } \\
\text { dos laptops educacionais. Assim, os resultados demonstraram-se } \\
\text { positivos e satisfatórios na opinião dos professores que efetiva- } \\
\text { mente fizeram parte da formação do UCA. }\end{array}$ \\
\hline $\begin{array}{l}\text { MULLER (2013) / UFRGS } \\
\text { Gonçalves. Metodologias intera- } \\
\text { tivas de ensino na formação de } \\
\text { professores de física: um estudo } \\
\text { de caso com o peer instruction. }\end{array}$ & $\begin{array}{l}\text { O estudo observou que as discussões entre colegas se mostraram } \\
\text { frutíferas, propiciando a participação ativa dos alunos e levando } \\
\text { à convergência para a resposta correta. A autora concluiu que a } \\
\text { metodologia pode ser aplicada com sucesso no contexto de uma } \\
\text { sala de aula do ensino médio, utilizando computadores do PROU- } \\
\text { CA com sistema de votação, dada as condições de infraestrutura } \\
\text { para usá-los pelo prédio de duração da aula. A participação ativa } \\
\text { dos alunos em sala de aula, aliada aos comentários positivos em } \\
\text { relação ao método, mostraram que é possível, através do método } \\
\text { IpC, modificar a dinâmica de sala de aula, aumentando significati- } \\
\text { vamente a interação interpessoal e a motivação dos alunos. }\end{array}$ \\
\hline $\begin{array}{l}\text { MARTINS (2013) / UFRGS } \\
\text { Práticas pedagógicas com o Plano } \\
\text { Ceibal para a inclusão escolar: es- } \\
\text { tudo de caso em escolas do Uru- } \\
\text { guai. }\end{array}$ & $\begin{array}{l}\text { Os resultados desta investigação evidenciaram a falta de preparo } \\
\text { para a implementação do Plano Ceibal e a falta de formação tec- } \\
\text { nológica, levando ao despreparo dos professores para o uso das } \\
\text { ferramentas oferecidas pelos computadores portáteis (X0). Obser- } \\
\text { vou-se, também, que as escolas e os professores não têm preparo } \\
\text { para utilizar os recursos tecnológicos com alunos com deficiência } \\
\text { e que, tecnologicamente, os computadores não permitem adapta- } \\
\text { ções de acessibilidade e tecnologia assistiva necessárias. } \\
\end{array}$ \\
\hline \begin{tabular}{l}
\multicolumn{1}{|c|}{ MACHADO (2013) / UDESC } \\
A docência e suas práticas a par- \\
tir da inserção dos computadores \\
móveis do projeto um computador \\
por aluno na Grande Florianópo- \\
lis: três realidades, um estudo.
\end{tabular} & $\begin{array}{l}\text { A partir de um total de } 50 \text { aulas assistidas e cerca de três horas de } \\
\text { entrevistas gravadas, o estudo apontou que as práticas docentes } \\
\text { desenvolvidas com os computadores móveis do PROUCA, ainda } \\
\text { encontram-se longe de serem consideradas como mediatizadoras, } \\
\text { visto que ainda repetem modelos estabelecidos pela profissão ao } \\
\text { longo da história. A pesquisa apontou, ainda, a necessidade do de- } \\
\text { senvolvimento e do aprofundamento de um currículo que alie as } \\
\text { possibilidades da TIDIC aos conteúdos escolares. }\end{array}$ \\
\hline
\end{tabular}


(Continuação)

\begin{tabular}{|c|c|}
\hline AUTOR/ANO/IES/TEMA & ACHADOS DA PESQUISA \\
\hline $\begin{array}{l}\text { LIMA FILHO (2013) / UFC } \\
\text { Aprendizagem colaborativa me- } \\
\text { diada pelo squeak. }\end{array}$ & $\begin{array}{l}\text { A pesquisa analisou a aprendizagem colaborativa, estudo dos con- } \\
\text { teúdos de Biologia e aprendizagem mediada pelo Squeak (ferra- } \\
\text { menta do laptop educacional). No decorrer da intervenção foram } \\
\text { analisados os momentos de interação entre pares e de socialização } \\
\text { das produções dos participantes, que se deu a partir da utilização } \\
\text { de um aplicativo, que possibilitou a criação de desenhos e ani- } \\
\text { mações para representar conteúdos de Biologia. Constatou-se que } \\
\text { as situações didáticas criadas pela intervenção ampliaram as in- } \\
\text { terações e que as tecnologias digitais podem oferecer benefícios } \\
\text { desde que utilizadas em uma perspectiva colaborativa, oferecendo } \\
\text { suporte e problematizando os conteúdos de Biologia. }\end{array}$ \\
\hline $\begin{array}{l}\text { CARVALHO (2013) / UECE } \\
\text { Contribuições da Teoria da Afeti- } \\
\text { vidade no ensino de funções com } \\
\text { o uso do laptop educacional. }\end{array}$ & $\begin{array}{l}\text { Constatou-se no estudo que a prática do professor avançou rumo a } \\
\text { trabalhar o conceito de função como um conhecimento socialmen- } \\
\text { te construído e de importância para a sociedade. Outro avanço per- } \\
\text { cebido foi o trabalho do professor com o objeto de aprendizagem } \\
\text { Grande Prêmio Funcional e o software Geogebra no ensino do } \\
\text { conteúdo de funções. Assim, o laptop educacional foi efetivamen- } \\
\text { te utilizado para que o ensino se transformasse em aprendizagem. }\end{array}$ \\
\hline $\begin{array}{l}\text { GUEDES (2013) / UFC } \\
\text { Elaboração de aulas com suporte } \\
\text { de objetos educacionais digitais: } \\
\text { estudo de caso realizado em uma } \\
\text { escola participante do Projeto Um } \\
\text { Computador Por Aluno (UCA) em } \\
\text { Fortaleza. }\end{array}$ & $\begin{array}{l}\text { A investigação observou que, considerando as dificuldades en- } \\
\text { contradas pelos professores da escola pesquisada, na ocasião da } \\
\text { seleção dos objetos educacionais, esses buscam os objetos mais } \\
\text { atrativos. Quanto à localização, a maioria das professoras tem uma } \\
\text { metodologia de pesquisa orientada por temas, interesses pedagó- } \\
\text { gicos e utilizava os motores de busca, e não os portais sugeridos } \\
\text { pelo curso de formação. Além disso, nenhuma professora sabia da } \\
\text { existência do BIOE, ferramenta apresentada na intervenção, o que } \\
\text { demonstra, segundo a pesquisadora, que existe uma má dissemina- } \\
\text { ção das ferramentas desenvolvidas pelo Ministério da Educação. }\end{array}$ \\
\hline $\begin{array}{l}\text { DOS SANTOS (2014) / UFPB } \\
\text { Competência em informação e } \\
\text { inclusão digital no Programa Um } \\
\text { Computador por Aluno. }\end{array}$ & $\begin{array}{l}\text { Analisa o PROUCA na perspectiva da Ciência da Informação a } \\
\text { partir dos estudos sobre inclusão digital, competência de informa- } \\
\text { ção, tecnologias intelectuais, políticas de informação e regime de } \\
\text { informação. A estratégia metodológica foi construída com base na } \\
\text { observação participante junto ao grupo de formação da Universi- } \\
\text { dade Federal do Ceará (IES Nacional). Os resultados apresentam } \\
\text { o regime de informação do PROUCA, identifica os atores, dispo- } \\
\text { sitivos, artefatos e ações de informação do programa. }\end{array}$ \\
\hline $\begin{array}{l}\text { MACALINI (2014)/UDESC } \\
\text { A inserção das tecnologias na } \\
\text { formação dos professores de arte: } \\
\text { um estudo com participantes do } \\
\text { PROUCA. }\end{array}$ & $\begin{array}{l}\text { A pesquisa procurou investigar a formação dos professores de Ar- } \\
\text { tes Visuais e o modo como ocorreu a inserção das tecnologias digi- } \\
\text { tais na sua prática pedagógica com um olhar sobre como os cursos } \\
\text { de formação docentes articulam o ensino de artes e tecnologia em } \\
\text { sala de aula, a partir da trajetória de professores de escolas partici- } \\
\text { pantes do PROUCA no estado de Santa Catarina. Com abordagem } \\
\text { qualitativa, a pesquisa envolveu a análise de documentos, revisão } \\
\text { bibliográfica, aplicação de questionários e entrevistas, bem como a } \\
\text { interação dos professores com a plataforma Moodle. }\end{array}$ \\
\hline
\end{tabular}


(Conclusão)

\begin{tabular}{|c|c|}
\hline AUTOR/ANO/IES/TEMA & ACHADOS DA PESQUISA \\
\hline \begin{tabular}{l}
\multicolumn{1}{c}{ DA SILVA (2014) / UDESC } \\
Os sentidos do trabalho docente \\
e usos das tecnologias digitais no \\
contexto do programa UCA.
\end{tabular} & $\begin{array}{l}\text { A pesquisa procurou compreender as implicações que as inserções } \\
\text { tecnológicas promovidas pelo PROUCA trouxeram para o sentido } \\
\text { do trabalho docente. Metodologicamente, foram entrevistados cin- } \\
\text { co professores de uma escola participante do programa na Grande } \\
\text { Florianópolis e por meio das entrevistas procurou-se aprofundar } \\
\text { a trajetória profissional dos professores participantes do estudo, } \\
\text { analisar a relação dos laptops educacionais com o trabalho dos } \\
\text { professores e os sentidos atribuídos a tais tecnologias e políticas e } \\
\text { tal análise foi efetuada a partir da Psicologia Histórico Cultural. A } \\
\text { pesquisa apontou que a maior a dos professores não incorporaram } \\
\text { de fato o laptop educacional em seu cotidiano de trabalho, utili- } \\
\text { zando a máquina esporadicamente e de maneira funcional, não in- } \\
\text { dicando que houve apropriação de práticas inovadoras nas práticas } \\
\text { pedagógicas. A necessidade de formação de professores se revelou } \\
\text { essencial, posto que esses não se sentem preparados para pensar os } \\
\text { usos das tecnologias digitais de forma autônoma. }\end{array}$ \\
\hline
\end{tabular}

FONTE: Os autores (2016).

Em linhas gerais, a análise dos achados das pesquisas apresentadas nos Quadros 1 e 2, apontam para a recorrência de aspectos positivos e negativos, a saber:

a) Aspectos positivos

- Incentivo a uma cultura colaborativa na construção do conhecimento;

- Presença dos laptops nas aulas proporciona maior aproximação entre professores e alunos e tal fato contribui para o processo de construção do conhecimento;

- Recorrência de discurso revolucionário do PROUCA com a expectativa de que as tecnologias transformariam o processo de ensino/ aprendizagem;

- Avanços significativos no processo de inclusão digital e uso instrumental das tecnologias digitais por professores e principalmente por estudantes.

b) Aspectos negativos

- Problemas na infraestrutura das escolas do UCA, especialmente, instalações e rede elétrica, deficiências na rede de internet, inadequações no ambiente da sala de aula e no local de armazenamento e guarda dos equipamentos;

- Subutilização dos recursos pedagógicos disponibilizados pelos laptops, com mera substituição dos cadernos de anotações pelos editores de texto, e dos livros, dicionários e enciclopédias pelos sites de busca; 
- Subdimensionamento e descontinuidade do processo de formação docente;

- Ausência de suporte técnico e da reposição de equipamentos.

Um programa da natureza e envergadura do PROUCA apresenta uma infinidade de possibilidades de pesquisas e consequentemente de resultados. Observou-se, contudo, que a potencialidade do programa foi prejudicada pela ausência de cultura digital nas escolas, com reflexos em sua infraestrutura. Igualmente, a baixa familiaridade dos profissionais com o uso de equipamentos, tais como o laptop educacional, provocou distorções como a tentativa de mera adaptação de tradicionais de mediação (aula expositiva, pesquisa de conteúdo, cópias e reprodução de textos) para o ambiente eletrônico (leitura de textos no computador, pesquisa em sites de busca, digitação em editores de texto), subutilizando, assim, as potencialidades dos recursos disponibilizados para as escolas.

\section{Considerações finais}

O conhecimento sobre as características bibliométricas ou informétricas da diversidade de pesquisas que são realizadas no ambiente acadêmico, especialmente as teses de doutorado e dissertações de mestrado, têm se revelado como instrumento de metaciência. Essa prática tem se mostrado fundamental para que os diversos ramos do conhecimento mensurem, descrevam e compreendam o processo de amadurecimento científico, que evidentemente não corre de maneira uniforme nas diversas áreas humanas. Por outro lado, a avaliação da produção científica pode ser utilizada como ferramenta para determinar padrões de uma política local e nacional de ensino e pesquisa, uma vez que através dela é possível obter-se diagnóstico das reais potencialidades de determinados grupos e/ ou instituições.

O estudo sobre as pesquisas de mestrado e doutorado em áreas tais como o uso de computadores individuais em escola pública (como propõe o PROUCA), auxilia na definição do perfil demográfico dessas pesquisas (autoria, orientação, instituição e região de origem, ano de elaboração, dentre outros), além de apontar tendências, lacunas, espaços de saturação, métodos mais recorrentes, obras de referência, dentre outros aspectos relevantes. Sob essa ótica, esta pesquisa objetivou analisar características demográficas e metodológicas das teses e dissertações produzidas no Brasil enfatizando temáticas relacionadas ao Programa Um Computador por Aluno (PROUCA), que foram publicadas entre os anos 2008 e 2014. 
Inicialmente, observou-se prevalência das dissertações sobre as teses e isso pode estar relacionado ao fato do PROUCA ser relativamente recente no país (implantando como projeto em 2007 e institucionalizado como programa em 2010), posto que as pesquisas de mestrado são mais curtas e, assim, conseguem captar mais rapidamente os fenômenos, ao contrário das pesquisas de doutorado, que são mais longas. Um dado que corrobora com tal explicação é o fato de a primeira tese de doutorado ter sido defendida apenas em 2011, exatamente quatro anos após a implantação do programa.

Apesar das pesquisas estarem distribuídas em 19 Instituições de Ensino Superior (IES), verificou-se elevada concentração em apenas seis delas: UFRGS, PUC-SP, UnB, UDESC, UFC e UERJ. Percebeu-se também que a maioria das pesquisas origina-se de universidades participantes do Grupo de Trabalho de Assessores Pedagógicos do PROUCA, seja como IES Global ou IES Local. Ressalte-se que quando a distribuição é realizada por estado, observa-se que cinco deles (Rio Grande do Sul, São Paulo, Distrito Federal, Santa Catarina e Ceará) concentram $81,4 \%$ da produção científica associada ao PROUCA.

Apesar da forte concentração de pesquisas em doutorados e mestrado em Educação, observou-se, ademais, diversidade de temas abordados, com destaque para as temáticas Processo de Ensino/Aprendizagem, Prática Docente, Formação de Professores e Tecnologias Digitais na Educação presentes em dois terços das pesquisas.

Por fim, foram mapeados 3.856 títulos bibliográficos distribuídos em sete categorias (livros, periódicos, eventos, teses/dissertações, documentos normativos, materiais da internet e outros). Curiosamente, apesar das pesquisas tratarem de um tema relacionado às tecnologias digitais, os livros impressos são o tipo de material bibliográfico hegemônico, demonstrando certo conservadorismo ou tradicionalismo dos pesquisadores. Por outro lado, houve ampla predominância de referências bibliográficas nacionais, acentuando-se quando o recorte é feito apenas nas dissertações.

\section{REFERÊNCIAS}

AIRES, L. Paradigma Qualitativo e Práticas de Investigação Educacional. Universidade Aberta: 2011. Disponível em <https://repositorioaberto.uab.pt/handle/10400.2/2028>. Acesso em: fev. 2015.

ALMEIDA, M. E. B. Tecnologias na educação: dos caminhos trilhados aos atuais desafios. BOLEMA - Boletim de Educação Matemática, n. 29, ano 21, 2008. 
ALMEIDA, M. E. B.; PRADO, M. E. B. B. Indicadores para a formação de educadores para a integração do laptop na escola. In: ALMEIDA, M. E. B.; PRADO, M. E. B. B. (Org.). O computador portátil na escola: mudanças e desafios nos processos de ensino e aprendizagem. São Paulo: Avercamp, 2011.

ARAUJO, C. M. de M.; SILVA, M. A. Contribuições do Laptop e da Rádio Escolar para a Aprendizagem. In: WORKSHOPS DO CONGRESSO BRASILEIRO DE INFORMÁTICA NA EDUCAÇÃO, Anais... 2012.

BORGES, M. K.; SANTOS, M. B. F. dos. Um retrospecto histórico do projeto OLPC no Brasil e no mundo. In: SEMINÁRIO DE PESQUISA EM EDUCAÇÃO DA REGIÃO SUL - ANPED SUL, 7. Anais... Itajaí, SC, 2008.

BUFREM, L.; PRATES, Y. O saber científico registrado e as práticas de mensuração da informação. Ciência da Informação. Brasília, v. 34, n. 2, p. 9-25, maio/ago. 2005. Disponível em: <http://www.scielo.br/pdf/ci/v34n2/28551>. Acesso em: fev. 2015.

CANAL, M. C.; MIRANDA, L. C. de.; ALMEIDA, L. D. A.; BARANAUSKAS, M. C. C. Analisando a Simplicidade do Laptop da OLPC: Desafios e Propostas de Soluções de Design. In: CONGRESSO DA SOCIEDADE BRASILEIRA DE COMPUTAÇÃO, 31. Anais... SBC, p. 1250-1264.

CARVALHO, A. B. ALVES, T. P. Apropriação tecnológica e cultura digital: O programa "Um computador por aluno" no interior do nordeste brasileiro. Logos, São Paulo: Avercamp, v. 1, n. 34, 2011.

CAVAlCANTE, A. P. P.; NASCIMENTO, K. A. S. do; CASTRO FILHO, J. A. de; Utilização do Laptop Educacional: discutindo as práticas Pedagógicas. SBIE - XVII WIE, 22. Anais... Aracaju, 2011.

CYSNEIROS, P. G.; CARVALHO, A. B. G.; PANERAI, T. O Programa UCA na Visão de Professores Multiplicadores. SBIE - XVII WIE, 22. Anais... Aracaju, 2011.

DOS SANTOS, R. N. M.; KOBASHI, N. Y. Bibliometria, cientometria, informetria: conceitos e aplicações. Pesquisa Brasileira em Ciência da Informação, Brasília, v. 2, n. 1, p. 155-172, jan./dez. 2009. Disponível em: <http://inseer.ibict.br/ancib/index.php/ tpbci/article/view/21/43>. Acesso em: fev. 2015.

FABRIS, L. L.; FINCO, M. D. Percepção de Escolares no Uso de Laptops Educacionais no Contexto do Projeto UCA. In: SIMPÓSIO BRASILEIRO DE INFORMÁTICA NA EDUCAÇÃO, 23. Anais... (SBIE, 2012).

FERRETE, A. A. S. S. O projeto um computador por aluno na escola EMEF Pedro Izídio de Oliveira: possibilidades e desafios. In: WORKSHOPS DO CONGRESSO BRASILEIRO DE INFORMÁTICA NA EDUCAÇÃO. Anais... 2012.

GATTI, B. A. A Construção da Pesquisa em Educação no Brasil. Brasília: Liber Livro Editora, 2007.

GIL, A. C. Métodos e técnicas de pesquisa social. São Paulo: Atlas, 1999. 
GOMES, C. A. O “Quali” versus "Quanti” na pesquisa em avaliação educacional: Uma análise de artigos publicados em periódicos brasileiros. In: AFIRSE Secção Brasileira, 7. Anais... Mossoró, 2013.

JOLY, M. C. R. A.; BERBERIAN, A. A.; ANDRADE, R. G.; TEIXEIRA, T. C. T. Análise de teses e dissertações em avaliação psicológica disponíveis na BVS-PSI Brasil. Psicologia: Ciência e Profissão, Brasília, v. 30, n. 1. Disponível em: <http://www.scielo.br/ scielo.php?pid=S1414-98932010000100013\&script=sci_arttext $>$.Acesso em: fev. 2015.

LOPES, M. I. V.; ROMANCINI, R. Teses e dissertações: estudo bibliométrico na área da comunicação. In: POBLACION, D. A; WITTER, G. P.; SILVA, J. F. M. (Org.). Comunicação \& produção científica: contexto, indicadores e avaliação. São Paulo: Angellara, 2006. p. 235-259.

MACULAN, B. C. M. S.; LIMA, G. A. B. O. Modelo para análise conceitual de teses e dissertações com vista à criação de taxonomia facetada. Informação \& Sociedades: estudos. João Pessoa, v. 21, n. 3, p. 41-54, set./dez. 2011. Disponível em: <http://www. ies.ufpb.br/ojs/index.php/ies/article/view/9582/6994>. Acesso em: fev. de 2015.

MINISTÉRIO DA EDUCAÇÃO (MEC). Termo de referência geral UCA-FNDE, 2010. Disponível em: <http://webcache.googleusercontent.com/search?q=cache:K3L12PjOlA sJ:ramec.mec.gov.br/index.php\%3Foption\%3Dcom_docman\%26task\%3Ddoc_downl oad $\% 26$ gid $\% 3 \mathrm{D} 1133 \% 26$ Itemid $\% 3 \mathrm{D} 1+\& \mathrm{~cd}=2 \& \mathrm{hl}=\mathrm{pt}-\mathrm{BR} \& \mathrm{ct}=\mathrm{clnk} \& \mathrm{gl}=\mathrm{br}>$. Acesso em: fev. de 2015.

MENDES, M.; ALMEIDA, M. E. Utilização do laptop educacional em sala de aula In: ALMEIDA, M.; PRADO, M. E. (Org.). O computador portátil na escola: mudanças e desafios nos processos de ensino e aprendizagem. São Paulo: Avercamp, 2011. p. 49-59.

MENESES, S. C. P. de. UCA - Um Computador Por Aluno: Era Da Inclusão Digital. SBIE - XVII WIE, 22. Anais... Aracaju, 21 a 25 de novembro de 2011.

NASCIMENTO, K. A. S.; MELO, M. B. O.; SILVA, M. A.; BARBOSA, J. R.; CASTRO FILHO, J. A. Programa UCA no Estado do Ceará: Caminhos Percorridos, Lições Aprendidas. SBIE - XVII WIE,22. Anais... Aracaju, 2011.

NORONHA, A. P. P.; ANDRADE, R. G.; MIGUEL, K.; NASCIMENTO, M. M.; NUNES, M. F. O.; PACANARO, S. V.; FERRUZZI, A. H.; SARTORI, F. A.; TAKAHASHI, L. T.; COZZA, H. F. P. Análise de teses e dissertações em orientação profissional. Revista Brasileira de Orientação Profissional. São Paulo, v. 7, n. 2, dez. 2006. Disponível em: <http:// pepsic.bvsalud.org/scielo.php?script=sci_arttext\&pid=S1679-33902006000200002>. Acesso em: fev. 2015.

PEREIRA, M. A. Colégios jesuíticos no Brasil colonial na produção científica de teses e dissertações. Dissertação (Mestrado em Educação) - Universidade Federal de São Carlos, 192p. São Carlos: 2009. Disponível em: <http://www.bdtd.ufscar.br/htdocs/ tedeSimplificado//tde_arquivos/8/TDE-2012-10-29T145653Z-4749/Publico/4631.pdf>. Acesso em: fev. 2015. 
PORTAL UCA. Conheça o UCA. Disponível em: <http://www.uca.gov.br/institucional/ projeto.jsp>. Acesso em: mar. 2013.

PORTAL UCA. Critério de seleção das escolas. Disponível em: < http://www.uca.gov. br/institucional/criteriosEscolha.jsp>. Acesso em: mar 2013.

RAMOS, H. S. C.; BRASCHER, M. Aplicação da descoberta de conhecimento em textos para apoio à construção de indicadores infométricos para a área de $\mathrm{C} \& \mathrm{~T}$. Ciência da Informação. Brasília, v. 38, n. 2, p. 56-68, maio/ago. 2009. Disponível em: <http://www. scielo.br/pdf/ci/v38n2/05.pdf>. Acesso em: fev. 2015.

TRAVIESO, J.; PLANELLA, J. La alfabetización digital como factor de inclusión social: una mirada crítica. Uocpapers, n. 7, Universitat Oberta de Catalunya, 2008.

VALENTE, J. A. Um laptop para cada aluno: promessas e resultados educacionais efetivos". In: ALMEIDA, M. E. B.; PRADO, M. E. B. B. (Org.). O computador portátil na escola: mudanças e desafios nos processos de ensino e aprendizagem. São Paulo: Avercamp, 2011.

VANTI, N. A. P. Da bibliometria à webometria: uma exploração conceitual dos mecanismos utilizados para medir o registro da informação e a difusão do conhecimento. Ciência da Informação, Brasília, v. 31, n. 2, maio/ago. 2002.

WELLMAN, B. Networks in the global village, life in contemporary communities. Bolder, Colorado: Westview Press, 1999.

Texto recebido em 24 de agosto de 2016. Texto aprovado em 03 de novembro de 2016. 